\title{
Avaliação da existência de controle de infecção oral nos pacientes internados em hospitais do estado do Rio de Janeiro
}

\author{
Evaluating the existence of oral infection control \\ in patients admitted in state hospitals in Rio de Janeiro
}

Sérgio Kahn ${ }^{1}$

Carlos Henrique Garcia ${ }^{1,2}$

J oão Galan Júnior ${ }^{1}$

Fátima M aria $\mathrm{Namen}^{1}$

Walter Augusto Soares Machado ${ }^{1}$

Joel Alves da Silva Júnior ${ }^{1}$

Eleanor M obley Scofield Sardenberg ${ }^{3}$

André M edina Egreja ${ }^{1}$

${ }^{1}$ Universidade Veiga de

Almeida. Rualbituruna 108,

Tijuca. 20271-020 Rio de Janeiro RJ.

skahn@openlink.com.br

${ }^{2}$ Universidade do Grande

Rio.

${ }^{3}$ Especialista em

Periodontia.
Abstract Theaim of the present study is to ascertain whether an oral infection control protocol is being used in Rio de Janeiro State hospitals. Sixty two hospitals, both public and private have been surveyed. When asked whether any procedure was being adopted with admitted patients (in case of ICU patients), 39\% of thehospitals responded positively. Among all institutions surveyed, only 15\% conduct a regular plaque control protocol in admitted patients. Studies have shown that there is an inter-relationship between periodontal disease and systemic diseases, such as cardiovascular disease, osteoporosis, preterm births and low birthweight, diabetes and respiratory diseases. Theoral cavity is considered a potent reservoir of respiratory pathogens. Based on these findings, it has become evident that oral hygiene is an important means of preventing a number of diseases. Thus the need arises not only to create an oral cavity infection control protocol that will contribute to reduce mortality in admitted patients but also to propose preventive measures towards this end. Key words Systemic diseases, Respiratory infection, Infection control, Bacterial plaque, Biofilm, Pneumonia
Resumo 0 objetivo do presente estudo foi verificar a existência de um protocolo de controle de infecção oral nos hospitais do Estado do Rio de Janeiro. Foram avaliados 62 hospitais da rede pública eprivada. Quando questionados se existia na instituição al gum procedimento destinado aos pacientes internados (no caso deUTIs), 39\% doshospitais pesquisados responderam positivamente. Das instituições pesquisadas, apenas $15 \%$ possuem um protocolo regular para o controle de placa nos pacientes internados. Pesquisas têm demonstrado a inter-relação da doença periodontal com doenças sistêmicas, como doenças cardiovasculares, osteoporose, nascimento de bebês de baixo peso e parto prematuro, diabetes e doenças respiratórias. A cavidade oral tem sido considerada como um potente reservatório de patógenos respiratórios. Diante destes fatos, evidencia-sea importância da higiene bucal como um meio de se prevenir patologias diversas. Desta forma, existea necessidadedesecriar um protocolo de controle de infecção da cavidade oral para contribuir para a redução da mortalidade de pacientes internados e propor medidas pre ventivas para este fim.

Palavras-chave Doença sistêmica, Infecção respiratória, Controle de infecção, Placa bacteriana, Biofilme, Pneumonia 
Introdução

As vias aéreas superiores são freqüentemente contaminadas por microorganismos derivados das regiões nasal, oral e faríngea. Inversamente, as vias aéreas inferiores, onde ocorrem as trocas gasosas, são geralmente mantidas livres de microorganismos por uma combinação de fatores imunes do hospedeiro e limpeza mecânica através de reflexo tussígeno, transporteciliar de contaminantes aspirados e movimento de secreções das vias aéreas inferiores para a traquéia ${ }^{1}$.

Com o grande progresso das pesquisas na área da saúde, um novo conceito, cada vez mais evidente, fortalece a inter-relação da doença periodontal com doenças sistêmicas. As evidências acumuladas sugerem que as doenças orais, principalmente a doença periodontal, podem influenciar o curso da infecção respiratória ${ }^{2}$. As doenças respiratórias são responsáveis por uma significativa parcela demorbidadeemortalidadeem pacientes de todas as idades.

A prevalência de colonização de patógenos respiratórios na placa e mucosa oral de um grupo de pacientes internados em UTI (Unidade de Tratamento Intensivo) foi comparada a um grupo de pacientes de uma clínica odontológica em tratamento clínico regular ${ }^{3}$. N os pacientes deUTI, a higiene oral foi mais pobre que nos pacientes clínicos. Placa dental e/ou mucosa oral de $65 \%$ dos pacientes de UTI apresentaram colonização por patógenos respiratórios, em contraste com apenas $16 \%$ dos pacientes clínicos. Os autores concluíram que a placa dental pode ser um importante reservatório de patógenos respiratórios eque a melhoria da higiene oral em pacientes internados pode reduzir a placa dental e possi bilitar a redução de colonização orofaríngea.

A efetividade de gluconato de clorexidina a $0,12 \%$ como descontaminante orofaríngeo foi testada em um grupo de 353 pacientes submetidos à cirurgia cardíaca ( $n=173$ grupo teste e $n=180$ grupo controle), comparando com uma solução placebo ${ }^{4}$. 0 índice de infecção nosocomial foi reduzido em $65 \%$, enquanto aincidência total de infecções do trato respiratório foi $69 \%$ menor no grupo de pacientes queutilizaram clorexidina no pré-operatório (bochecho) e pósoperatório (solução rigorosamente aplicada na bochecha, faringe, gengiva, língua e superfícies dentárias por 30 segundos, duas vezes ao dia). Esses pesquisadores também notaram uma redução de $43 \%$ no uso de antibioticoterapia nãoprofilática nos pacientes tratados com clorexidina. Finalmente, a taxa demortalidadetotal foi de
$1,16 \%$ no grupo tratado com clorexidina contra $5,56 \%$ no grupo placebo.

A prevalência de gengivite em crianças com asma mostrou-se significativamente maior que no grupo controle, podendo ser explicado, em parte, por uma alteração na resposta imune e devido à desidratação da mucosa alveolar pela tendência de respiração bucal por estes pacientes, especial mente durante os episódios de rinite ou ataque asmático agudo ${ }^{5}$.

A importância da utilização de solução antimicrobiana como coadjuvante ou método principal para higiene oral de idosos ou indivíduos com deficiência física foi enfatizado por Okuda et al. ${ }^{6}$, objetivando, com isto, prevenir doenças sistêmicas como pneumonia bacteriana e endocardites. Os autores citaram, como solução antimicrobiana oral, uma substância contendo derivados fenólicos como o timol, gluconato de clorexidina, cloridrato de cetilpiridíneo, triclosan e povidine.

A cavidade oral tem sido considerada um potente reservatório para os patógenos respiratórios e a pneumonia nosocomial é a segunda infecção mais comum nas instituições de caridade, representando aproximadamente de 10 a 15\% do total de infecções adquiridas em hospitais, sendo que 20 a $50 \%$ dos pacientes afetados morrem por causa da infecção ${ }^{7}$. As condições que predispõem à aspiração de patógenos orais ou secreções orofaríngeas são epilepsia, derramecerebral, doença de Parkinson e alcoolismo. A doença periodontal e a pobre higienização bucal podem resultar em uma maior concentração dos patógenos orais na saliva, podendo ser aspirados para dentro do pulmão, confundindo a defesa imunológica. Os patógenos periodontais podem facilitar a colonização dos patógenos pulmonares nas vias aéreas superiores.

A efetividade da solução oral de gluconato de clorexidina a 0,12\%, comparado ao Listerine (mistura fenólica), foi testada como meio de diminuir a colonização bacteriana do trato respiratório, e assim, reduzir a pneumonia nosocomial em pacientes submetidos à cirurgia cardíaca aberta ${ }^{8}$. N os pacientes entubados por mais de 24 horas que mostraram alto grau de crescimento bacteriano na cultura de amostras de escarro coletadas durante a extubação, a taxa de pneumonia foi $71 \%$ menor no grupo de pacientes em que foi utilizado o gluconato de clorexidina para limpeza das superfícies da cavidade oral no prée pós-operatório.

Em um estudo de dois anos de duração com pacientes idosos, em asilo, Yoneyama et al..$^{9}$ con- 
cluíram que cuidados de higiene oral podem ser úteis na prevenção de pneumonia em idosos. No grupo de idosos que receberam cuidados de higieneoral regular, a incidência depneumonia eo número de pacientes que morreram em conseqüência de pneumonia foi significativamente menor que no grupo de idosos que não receberam tais cuidados.

A eficácia de cuidados profissionais de higie ne oral em idosos executados por higienista uma vez por semana foi avaliada durante 24 meses $^{10}$. Os autores concluíram que a prevalência de febre e a proporção de óbito decorrente de pneumonia por aspiração foram significativamente menores no grupo de pacientes com cuidados de higiene oral profissional, quando comparado com o grupo que não recebeu tais cuidados.

A pneumonia por aspiração tem como principal via de ocorrência a aspiração de conteúdos da orofaringe. Os autores concluem também que a higiene oral éum importante fator no combate à pneumonia por aspiração, pois a placa bacteriana pode atuar como reservatório de patógenos respiratórios. Diabéticos, idosos, imunossuprimidos, pacientes com doenças pulmonares ecom doença periodontal devem receber cuidados redobrados por serem mais suscetíveis à aspiração de secreções da orofaringe, e mais vulneráveis à colonização de bacilos Gram-negativos e bacté rias anaeróbias, que são as principais responsáveis pelo desenvolvimento de pneumonia por aspiração ${ }^{11}$.

\section{Objetivo}

O objetivo do presenteestudo foi verificar seexiste algum protocolo de controle de infecção oral nos hospitais do estado do Rio de Janeiro e saber quais são os procedimentos dehigiene bucal adotados com pacientes internados.

\section{Métodos}

Para a obtenção de dados sobre o assunto proposto, foi elaborado um questionário contendo três questões dicotômicas, três questões demúltipla escol ha e uma questão aberta, que fora posteriormente enviado a 62 hospitais do estado do Rio de Janeiro, localizados em diferentes municípios. Este universo englobou 25 hospitais particulares $(41 \%)$, doze hospitais públicos municipais (20\%), sete hospitais públicos estaduais $(11 \%)$, sete hospitais militares ( $11 \%)$, 4 hospitais públicos federais ( $6 \%)$, quatro hospitais universitários (6\%) e três hospitais filantrópicos (5\%).

Os questionários foram enviados aos hospitais acompanhados com requisição de autorização prévia utilizando-se para tal fax, correio eletrônico ou contato direto.

Como a intenção era saber se as instituições adotavam protocolos de controle de infecção oral e saber quais eram seus procedimentos com pacientes internados em relação a este assunto, os profissionais em questão deveriam ter contato direto com os pacientes, ou então, deveriam ter pleno conhecimento das medidas de controle de infecção oral que eram realizadas ou não no local. Os profissionais qualificados para responder às questões foram dentistas, médicos, enfermeiros ou auxiliares de enfermagem.

As questões que foram respondidas nas instituições pesquisadas constam no Anexo 1 .

\section{Resultados}

Das instituições que fizeram parte deste estudo, $32 \%$ afirmaram que quando um pacienteéinternado para realização deum procedimento cirúrgico, este é submetido anteriormente a uma avaliação da cavidade bucal, enquanto $53 \%$ dos hospitais pesquisados não realizam tal conduta. Um total de $15 \%$ dos entrevistados não responderam este quesito. Os principais dados avaliados pelos hospitais que avaliam a cavidade bucal de tais pacientes são apresentados no Gráfico 1.

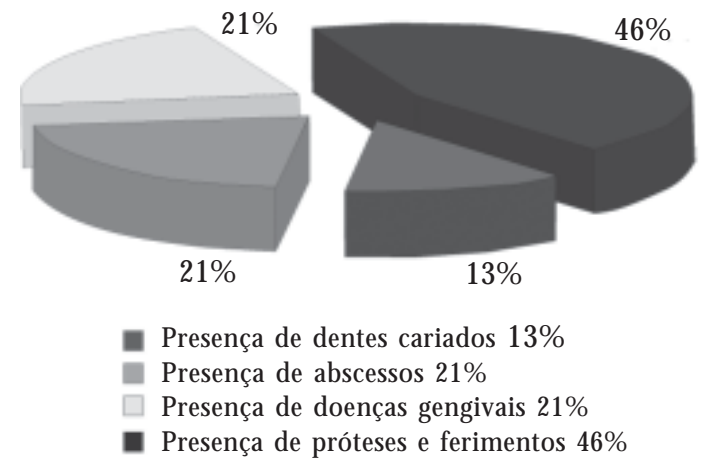

Gráfico 1. Dados avaliados na cavidade bucal nas inspeções pré-cirúrgicas. 
Quando questionados se existia no hospital em questão um protocolo para o controle de placa bacteriana nos pacientes internados, $15 \%$ das instituições responderam positivamente enquanto $85 \%$ afirmaram não haver nenhuma conduta específica para tal controle. Os resultados dos mé todos de higiene oral utilizados pelas instituições que fazem controle de placa bacteriana nos pacientes internados são mostrados no Gráfico 2.

A utilização de solução anti-séptica foi o mé todo de higiene oral predominante utilizado nos pacientes internados nos hospitais pesquisados. Deste montante, o Gráfico 3 apresenta o percen-

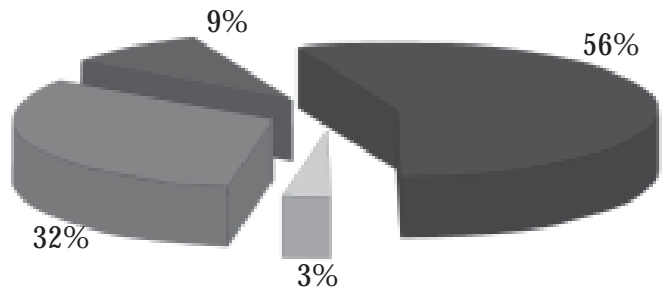

Escova dental $32 \%$

Fio dental 9\%

Solução anti-séptica 56\%

- Outros $3 \%$

Gráfico 2. M étodos de higiene oral empregados nos pacientes internados.

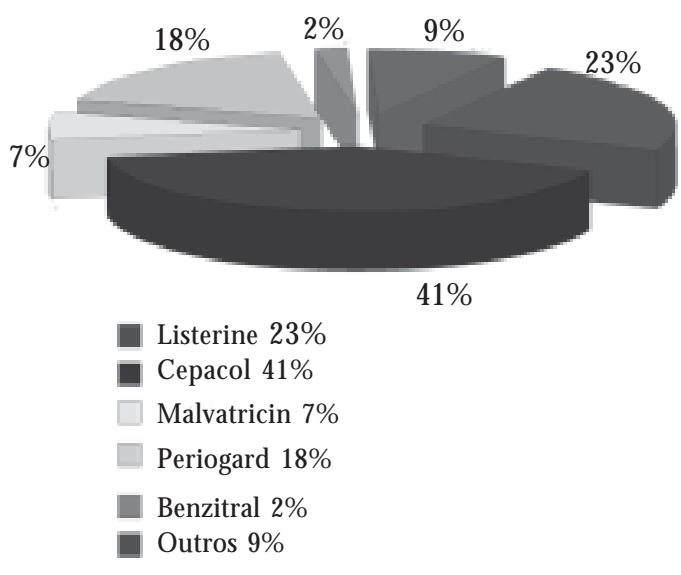

Gráfico 3. Soluções anti-sépticas utilizadas para controle de placa bacteriana nos pacientes internados. tual dos hospitais e as respectivas soluções utilizadas pelos mesmos.

Quando questionados se existia na instituição algum procedimento destinado aos pacientes internados, impossibilitados de realizarem, por si somente, a prática de métodos mecânicos equímicos deremoção deplaca (no caso deUTIs), $39 \%$ dos hospitais pesquisados responderam positivamente, $13 \%$ não responderam e $48 \%$ responderam negativamente. Os principais métodos de controle de placa bacteriana utilizados pelos hospitais que o fazem são apresentados no Gráfico 4.

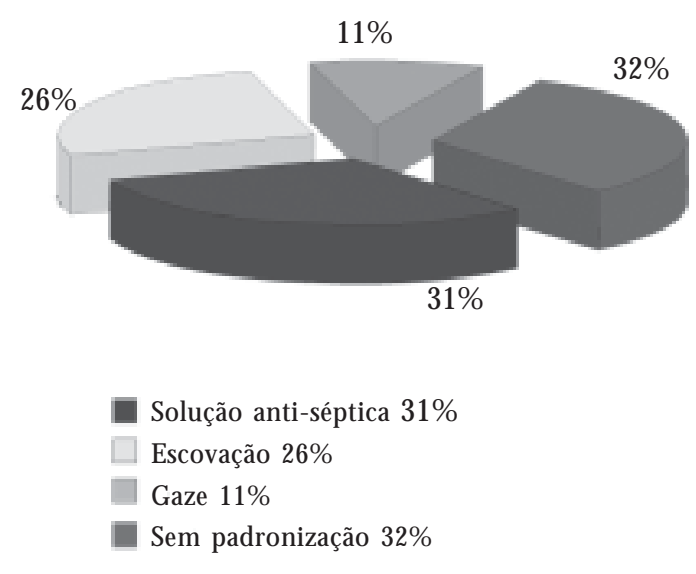

Gráfico 4. M étodos de higiene oral utilizados em pacientes internados em UTI. 


\section{Discussão econsiderações finais}

A cavidade oral, no que diz respeito às doenças periodontais e a certas desordens sistêmicas, tem um importante papel em infecções adquiridas em hospitais e enfermarias, especialmente infecções do trato respiratório ${ }^{12}$. Tem sido demonstrado quehigiene oral mecânica com ou sem anti-sépticos como o gluconato de clorexidina a $0,12 \%$ não somente reduz a prevalência de colonização por patógenos orais mas também reduz a ocorrência de pneumonias em $50 \%$. As doenças pulmonares obstrutivas crônicas também têm grande correlação com saúde oral deficiente. É possível que mediadores do hospedeiro, como citocinas e prostaglandinas, que são elevadas na saliva de indivíduos com doença periodontal, promovam inflamação pulmonar e infecção se aspiradas para as vias aéreas baixas. Três vias ligam infecções orais e efeitos sistêmicos: toxinas e produtos deinfecção como resultado de bacteremia; injúrias metastáticas devido à circulação de toxinas de bactérias orais e o processo inflamatório que estes microorganismos provocam.

Os resultados obtidos dos questionários respondidos pela amostragem da pesquisa apontam um sério descaso por parte dos dirigentes e profissionais de saúdeno quediz respeito ao controle de infecção da cavidade oral de pacientes internados nos hospitais do estado do Rio de Janeiro. O s estabelecimentos de saúde que realizam inspeção da cavidade oral dos pacientes antes das cirurgias ( $32 \%$ da amostra) em sua maioria objetivam principalmentea verificação da existência de próteses e ferimentos, possivelmente preocupados com uma possível deglutição das mesmas (próteses removíveis). Um percentual relativamentebaixo ( $21 \%$ dos que realizam a inspeção oral pré-cirúrgica) está preocupado com a existência de doenças gengivais.

A cavidade oral é o primeiro portal de entrada para microorganismos patogênicos que causam infecções sistêmicas, sendo a pneumonia uma delas ${ }^{13}$. A pneumonia por aspiração éo tipo mais comum de pneumonia nosocomial eéuma infecção prevalente, de alto custo e representa uma significativa causa de morbidade e mortalidade $^{14}$. A ausência de atenção com a higiene bucal resulta no aumento da quantidade e complexidade da placa dental, que pode favorecer a interação bacteriana entre bactérias indígenas da placa e patógenos respiratórios como P. aeruginosa e bacilos entéricos. Essas interações podem resultar na colonização da placa dental pelos patógenos respiratórios. A placa dental pode, além disso, atuar como um reservatório para a colonização dos patógenos respiratórios, que podem ser encontrados na saliva7. A contaminação da porção distal da árvore respiratória pela saliva contém certos microorganismos que podem provocar infecções respiratórias ${ }^{15}$.

As bactérias orais podem ser liberadas da placa bacteriana dental para as secreções salivares, podendo então ser aspiradas no trato respiratório inferior e causar doença respiratória, especialmentenos pacientes com doença periodontal ${ }^{16}$. U ma variedade de microorganismos anaeróbios orais e espécies facultativas, considerados como agentes etiológicos na patogênese da doença periodontal, têm sido cultivados a partir dos fluidos de pulmões infectados.

Diante disto, o investimento em implementação de protocolos decuidados com a saúdeoral para diminuir riscos de doenças sistêmicas infecciosas é uma medida de grande valia para a saúde pública e privada. Esta concepção é adotada somenteem $15 \%$ dasinstituições pesquisadase, destas, o método dehigiene oral mais empregado em seus protocolos para pacientes internados éa utilização de soluções anti-sépticas seguida de escovação dentária. M edidas simples como limpar os dentes dos pacientes com escovas dentais duas vezes ao dia e realizar uma profilaxia profissional na cavidade oral uma vez por semana mostraram reduções na mortalidade dos pacientes que contraíram pneumonia durante o período de internação ${ }^{9}$. Outra fácil medida para uma significativa descontaminação da cavidade oral e concomitante redução da incidência de infecção nosocomial em pacientes internados em UTI para cirurgia cardiovascular foi a utilização de digluconato de clorexidina a 0,12\% duas vezes ao dia ${ }^{4}$. No presente estudo, 39\% dos hospitais pesquisados relataram existir algum procedimento decontrole deinfecção oral em pacientes internados em UTI, sendo que, deste universo, a maioria não apresenta uma padronização de procedimentos.

Os resultados do presente estudo demonstraram que, em geral, não existe um protocolo decontrole de infecção da cavidade oral nos principais hospitais da rede pública e privada do estado do Rio de Janeiro. A implementação de tal protocolo poderá ajudar, em parte, a diminuir a morbidade e mortalidade de pacientes internados em UTI. 
Anexo 1

1 - Quando um paciente é internado para realização de um procedimento cirúrgico, este ésubmetido anteriormente a uma avaliação da cavidade bucal?

( ) Sim

( ) Não

2 - Em caso afirmativo, qual o principal dado avaliado?

( ) Presença de dentes cariados

( ) Presença de abscessos

( ) Presença de doenças gengivais

( ) Presença de ferimentos e próteses

3 - Existe neste hospital um protocolo para o controle de placa bacteriana nos pacientes internados?

( ) Sim

( ) Não

4 - Em caso afirmativo, qual o método empregado?

( ) Escova dental

( ) Fio dental

( ) Solução anti-séptica

( ) Outros

5 - No caso de uso de uma solução anti-séptica, qual a substância utilizada pelo hospital?

( ) LISTERINE (timol, ácido benzóico, salicilato de metila, eucaliptol, mentol)

( ) CEPACOL (cloreto de cetilpiridíneo)

( ) M ALVATRICIN (hidrolato de malvas, quinosol, fluoreto de sódio e tirotricina)

( ) PERIOGARD (gluconato de clorexidina)

( ) BEN ZITRAT (cloridrato de benzidramina)

( ) OUTROS

6 - Existe al gum procedimento destinado aos pacientes internados, impossibilitados de realizarem, por si somente, a prática de métodos mecânicos e químicos de remoção de placa (no caso de UTIs)?

( ) Sim

( ) Não

7 - Em caso afirmativo, qual? 


\section{Colaboradores}

S Kahn trabalhou na concepção teórica, elaboração e redação final do texto; $\mathrm{CH}$ Garcia eWAS $M$ achado orientaram a revisão e foram responsáveis por leituras críticas do texto; J Galan Jr e FM Namen contribuíram com a revisão e substanciaram a discussão teórica; AM Egreja, JA da Silva Jr e SEM Sardenberg executaram a parte experimental.

\section{Referências}

1. Ahmed QA, Niederman MS. Respiratory infection in the chronically critically ill patient. Ventilatorassociated pneumonia and tracheobronchitis. Clin Chest M ed 2001; 22:71-85.

2. Genco RJ. M edicina periodontal. 1a ed. São Paulo: Editora Santos; 2002.

3. Scannapieco FA, Stewart EM, Mylotte JM. Colonization of dental plaque by respiratory pathogens in medical intensive care patients. Crit Care M ed 1992; 20:740-745.

4. De Riso AJ, Dillon TA, Peterson AC. Chlorhexidine gluconate $0,12 \%$ oral rinse reduces the incidence of total nosocomial respiratory infection and nonprophylactic systemic antibiotic use in patients undergoing heart surgery. Chest 1996; 109(6):1556-1561.

5. M CDerra EJC, Pollard MA, Curzon MEJ. The dental status of asthmatic British school children. Pediatric Dentistry 1998; 20(4):281-287.

6. Okuda K, Adachi M, Iijima K. The efficacy of antimicrobial mouth rinses in oral health care. Bull Tokyo Dent Coll 1998; 39(1):7-14.

7. Mojon P. Oral health and respiratory infection. J Can Dent Assoc 2002; 68:340-345.

8. Houston S, Hougland P, Anderson JJ, Larocco M, Kennedy V, Gentry LO. Effectiveness of 0,12\% chlorhexidine gluconate oral rinse in reducing prevalence of nosocomial pneumonia en patients undergoing heart surgery. Am J Crit Care 2002; 11:567-570.

9. Yoneyama T, Yoshida M, Ohrui T. Oral care reduces pneumonia in older patients in nursing homes. J Am Geriatr Soc 2002; 50:430-433.

10. Adachi M, Ishihara K, Abe S, Okuda K, Ishikawa T. Effect of professional oral health care on the elderly living in nursing homes. Oral Surg Oral Med Oral Pathol Oral Radiol Endod 2002 94:191-195.

11. Kahn S, Sardenberg E, Silva LR, Machado WAS, AIves J. Pneumonia por aspiração associada à doença periodontal. Rev Bras Odontol 2003; 60(4):244-246.

12. Teng YA, Taylor GW, Scannapieco FA, Kinane DF, Curtis M, Beck JG, Kogon S. Periodontal health and systemic disorders. J Can Dent Assoc 2002; 68(3): 188-192.

13. Limeback H. Implications of oral infections on systemic diseases in the institutionalized elderly with a special focus on pneumonia. Ann Periodontol 1998; 3(1):262-275.

14. Scannapieco FA, Mylotte JM. Relationships between periodontal disease and bacterial pneumonia. J Periodontol 1999; 67(10):1114-1122.

15. Terpenning MS. The relationships between infections and chronic respiratory diseases: a overview. Ann Periodontol 2001; 6:66-70.

16. Finegold SM. Aspiration pneumonia. Rev Infect Dis 1991; 13:737-742. 